\title{
Modeling the Decision Process of Optimal Travel Route based on Analytic Hierarchy Process
}

\author{
Peng Cui ${ }^{1}$ and Xiaoying Wang ${ }^{1, *}$ \\ ${ }^{1}$ State Key Laboratory of Plateau Ecology and Agriculture, Department of \\ Computer Technology and Applications, Qinghai University, Xining, China, \\ 810016 \\ *wxy_cta@qhu.edu.cn
}

\begin{abstract}
In recent years, the number of tourists of domestic travel as well as travel route recommendations on the travel websites are growing fast. Tourists have difficulty in choosing optimal travel route. To solve this problem, we offer a decision model about optimal travel route based on Analytic Hierarchy Process(AHP). By collecting and analyzing the existing data from various travel websites, this model can recommend the optimal travel route to the users, offering them convenience when making choices. In this model, multiple selection factors (decision criterion), which were concerned by consumer, are taken into account and then decision criterions will be ranked synthetically by establishing the hierarchy model of these factors. Finally, judgement and sort for travel route are made based on the decision criterions, and then the final results could be obtained by means of conformance testing. Based on above work, the optimal travel route could be decided and given out.
\end{abstract}

Keywords: cloud computing, optimal travel route, decision model, judgment matrix, AHP

\section{Introduction}

With the rapid development of economy in China, the number of tourists of domestic travel is more and more. According to the data issued by National Bureau of Statistics of China, the consumption of tourism is increasing fast year by year. According to Cai Lijun et al. [1], who did some domestic tourism consumption surveys, we can see that domestic consumption of tourism is increasing year by year. However, in recent years, with the improvement of travel expenditure, travel routes offered by travel websites are also increasing. For some popular cities, there are many routes which include the same departure and destination. For example, data collected from Tongcheng website [2] show that there are 297 routes about a 5-day package tour from Beijing to Sanya. This means people have a lot of difficulty in choosing suitable travel route for themselves. The traditional method for users is to make a comparison among different travel websites with similar routes, including price, travel time, attractions arrangement and other information. Obviously this is a time and labor consuming work for the users. Therefore, in order to solve above problem, this paper proposes a decision model about of optimal travel route based on Analytic Hierarchy Process(AHP).

In recent years, there have already been some reports about decision-making of travel routes and also researches and applications of Analytic Hierarchy Process (AHP). Ma Zhangbao et al. [3], who began with the space decision-making of tourism travel, studied methods and techniques of the tourism travel decision support system, then proposed the operational model of travel combining space and time and the LBS model of tourism travel route. However, the model proposed in their paper focuses on querying attractions 
and hotels based on space, time and location service, and then provides users with query service of the optimal destination as well as the scheme to arrive at destination. All of these were not combined with schemes given by online travel websites. As a result, it is too complicated for users to use and unsuitable for general users to use or to design comprehensive online travel website decision-making system. Jin Baohui et al. [4] designed a travel route choice model based on Regret Theory and figured out the deficiency of Expect Utility Theory and Prospect Theory via comparison, and then proposed a simpler travel route choice model. This paper focuses on description of tourists' behavior in selecting routes, and then presents a selection model for tourists under uncertain conditions. It didn't do comprehensive comparison and sorting for travel routes, even didn't discuss about actual problems. Also, travel information provided by online travel sites, which provides big data source, were totally ignored in their work. In contrast, we combine existing research results of travel decision-making with the current travel background and user requirements, and propose the decision model about optimal travel route based on Analytic Hierarchy Process (AHP) focuses on doing comprehensive assessment and sorting for travel routes provided online, and then the optimal travel route from a host of travel routes could be obtained. To design decision-making method, we refer to the City Tourism Competitiveness Evaluation Index System based on AHP established by WangLi et al.[5] and the Fuzzy Multi-criteria Decision-making studied by Li Guangxu et al. [6]. WangLi et al. [5] has made comprehensive evaluation on present city tourism competitiveness using AHP in their work. Li Guangxu et al. [6] made comparison and analysis among a simple linear weighting method, Analytic Hierarchy Process(AHP), ANP grid analytic hierarchy process, and also the ideal solution and Rally operator method. Through the analysis of method for multi criteria decision making, it is concluded that analytic hierarchy process (AHP) can be improved slightly and is suitable to be used in solving travel decision-making problems.

There are already some work taking about researches and applications of AHP model. Duen-Ren Liu et al. [7] proposed to integrate AHP and data mining for product recommendation based on customer lifetime value, and then the user purchase intention decision model could be established. They combined AHP model with data mining techniques and applied them into the field of product recommendations. Mridul Gupta et al. [8] devised a user-centered network selection based on AHP decision algorithm, through the establishment of network selection decision-making model for users, applying Analytic Hierarchy Process (AHP) to the network selection decision-making problems. Turan Erman Erkan et al [9] selected the optimal warehouse data collecting system by using AHP and FAHP (Fuzzy Analytical Hierarchy Process) methods, through the establishment of hierarchy decision model used in company warehouse in data acquisition system to make a choice between the bar code and RFID systems. By examining and analyzing these existing research results, here in this paper we propose a decision model to calculate optimal travel route based on Analytic Hierarchy Process (AHP).

\section{Design and Implementation of the Decision Support Model}

\subsection{Introduction of the Decision-making Support System}

The designed decision-making support model in this paper refers to comprehensive assessment decision model and fuzzy assessment model based on AHP (Analytic Hierarchy Process). Analytic Hierarchy Process(AHP) is a multi-objective decision-making method set up by American famous operational research experts T.L. Saaty in the mid 70s. Its essence is to try to make people's thinking structured and hierarchical. This method can simply quantify the design thinking process of complex system[10].

To choose optimal travel routes, we need a certain assessment method to evaluate. In 
this paper, we use relative subjective AHP (Analytic Hierarchy Process) and fuzzy assessment to make comprehensive assessment and sort the candidate travel routes. The workflow of method used in this paper.

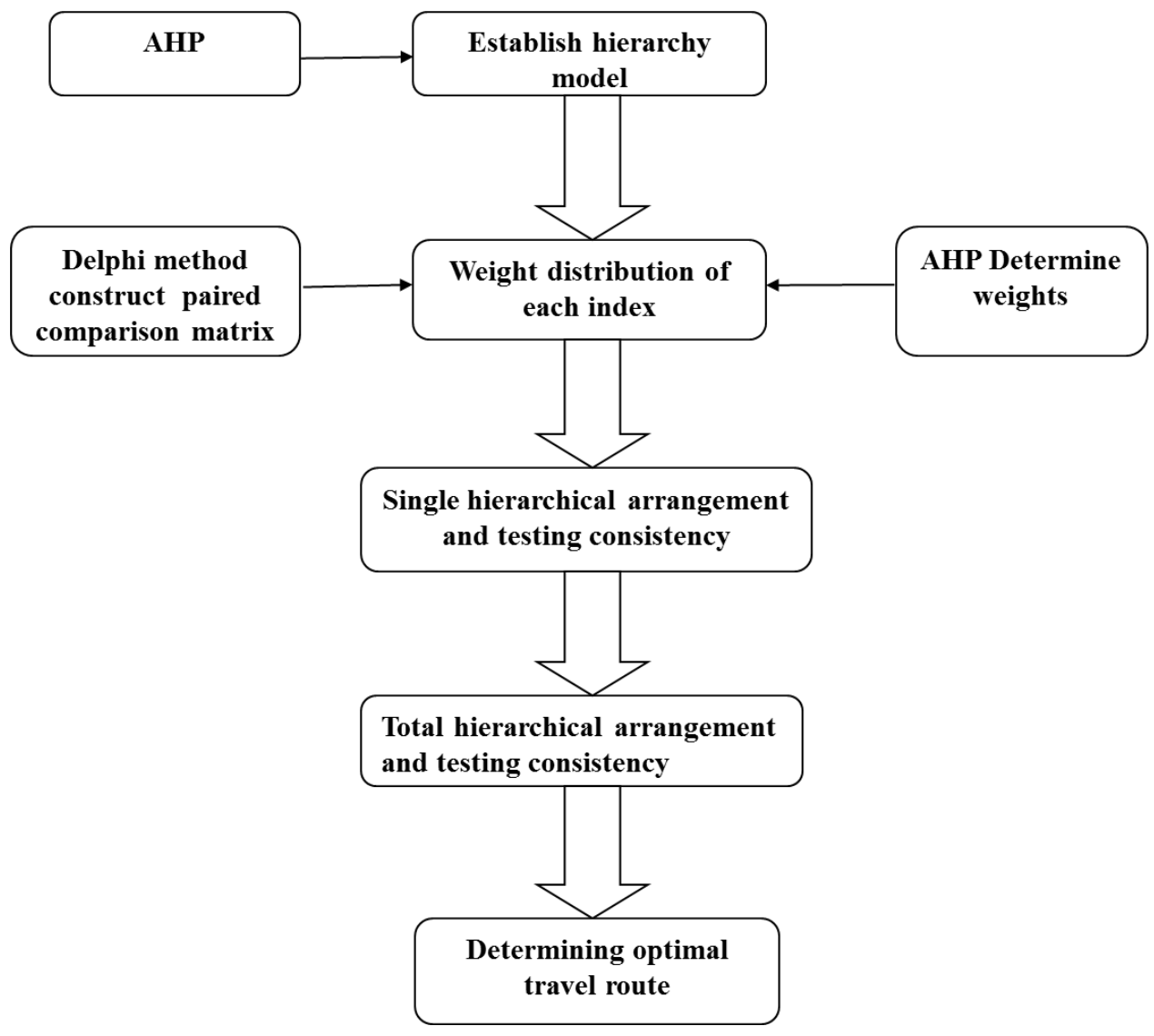

Figure 1. Decision Support Model of Travel Route

\subsubsection{Steps of AHP Modeling}

The steps of modeling the analytic hierarchy process include: 1) establishing the hierarchical structure model, 2) constructing judgment matrixes, 3) single ordering of hierarchy and testing consistency and 4) total ordering of hierarchy and testing consistency. Specific implementation is described as follows:

\section{(1) Establishing Hierarchical Structure Model}

The objectives of the decision, factors (decision criteria) and decision-making objects are divided into three layers: the highest, the middle and the lowest, then hierarchical structure diagram could be drawn out based on these layers. In this paper, Z represents goal layer. A represents criterion layer, B represents scheme layer.

\section{(2) Constructing Judgment Matrix}

After establishment of the hierarchical structure, relationship between elements of the upper and lower layers could be determined. If the element $C_{k}$ of the upper layer is a criterion and is dominant to the elements $\mathrm{A}_{1}, \mathrm{~A}_{2}, \ldots, \mathrm{A}_{\mathrm{n}}$ at the next layer, our purpose is to give $A_{1}, A_{2}, \ldots, A_{n}$ the corresponding weights according to their relative importance under criterion $C_{k}$.

Take two factors $x_{i}$ and $x_{j}$ each time. Denote as the ratio of the influence of $x_{i}$ and $x_{j}$ on $Z$. All comparison results are expressed as a matrix $A=\left(a_{i j}\right)_{n x n}$, which is called judgment 
matrix of between $Z$ and $X$. It's obvious to see that if effect of $x_{i}$ and $x_{j}$ on $Z$ is $a_{i j}$, then influence of $x_{i}$ and $x_{j}$ on the $Z$ ratio should be $a_{j i}=1 / a_{i j}$. To determine the value of $a_{i j}$, we use reference numbers 1-9 and their reciprocal as the scale, as shown in Table 1.

Table 1. Meanings of Reference Numbers

\begin{tabular}{|l|l|}
\hline Scaling & Meaning \\
\hline 1 & Indicates that the two factors are of equal importance. \\
\hline 3 & $\begin{array}{l}\text { Indicates that the two factor is slightly important than the other } \\
\text { one. }\end{array}$ \\
\hline 7 & $\begin{array}{l}\text { Indicates that the two factor is obviously important than the } \\
\text { other one. }\end{array}$ \\
\hline 9 & $\begin{array}{l}\text { Indicates that the two factor is strongly important than the other } \\
\text { one. }\end{array}$ \\
\hline $2,4,6,8$ & $\begin{array}{l}\text { Indicates that the two factor is Extremely important than the } \\
\text { other one. }\end{array}$ \\
\hline Reciprocal & $\begin{array}{l}\text { Median of the two adjacent judgments } \\
\text { factors } j \text { and } i \text { to determine the } a_{\mathrm{ji}}, \quad a_{i j}=1 / a_{j i}\end{array}$ \\
\hline
\end{tabular}

\section{(3) Single ordering of hierarchy and testing consistency}

Judge matrix $A$ corresponding to the maximum eigenvalue $\lambda_{\max }$ and get the eigenvector $W$, which after normalization will be corresponding weight factors denoting the relative importance of the current layer to upper layer. Such process is called single hierarchical sort.[11]

$N$ order positive reciprocal matrix $A$ is uniform matrix, whose maximum characteristic root is $\lambda_{m a x}=n$, When $A$ is in the consistency of existence of errors, there must be $\lambda_{\max }>n$. The greater the error is greater, the larger value of $\lambda_{\max }-n$ is greater.

We can check whether the judgment matrix $A$ is the consistent matrix by checking whether $\lambda_{\max }$ is equal to $N$. Since the characteristic root relying on $\mathrm{a}_{\mathrm{ij}}, \lambda_{\max }$ is much greater than $A$. Hence, the inconsistency degree of $A$ is also more significant, which means that $\lambda_{\max }$ corresponding to standard characteristic vector cannot be truly reflected in impact of factors on the $Z$ of proportion of $X=\left\{X_{1}, \cdots, X_{n}\right\}$. Therefore, it is necessary to make a consistency test to judgment matrix provided by decision makers, in order to determine whether it can accept it or not.

The procedure for checking consistency of the judgment matrix is as follows.

(1) Calculate consistency index $C I$

$a=\frac{\lambda_{\max }-n}{n-1}$

(2) Find the corresponding average random consistency index $R I$. For $n=1,2, \cdots, 9$, there is the value of $R I$, as shown in Table 2: 
Table 2. RI Values for Different Matrix Sizes

\begin{tabular}{|l|l|l|l|l|l|l|l|l|l|l|l|}
\hline $\mathrm{n}$ & 1 & 2 & 3 & 4 & 5 & 6 & 7 & 8 & 9 & 10 & 11 \\
\hline $\mathrm{RI}$ & 0 & 0 & 0.58 & 0.90 & 1.12 & 1.24 & 1.32 & 1.41 & 1.45 & 1.49 & 1.52 \\
\hline
\end{tabular}

(3) Calculate the consistency ratio $C R$

$C R=\frac{a}{R}$

When $C R<0.10$, the consistency of the judgment matrix is acceptable, and otherwise the judgment matrix should be properly modified.

\section{(4) Total Ordering of Hierarchy and Testing Consistency}

What we get from above is a group of elements on weight vector of a certain element in the upper layer. We are finally going to get to various elements, especially in the lowest layer of program for the goal of sort of weight, so as to choose the program. Total sorting weight to top down weight of the single criteria for synthesis.

Assuming that the upper layer (A layer) contains $m$ factors: $A_{1}, A_{2}, \cdots, A_{m}$, and their weights of total ordering of hierarchy are $\mathrm{a}_{1}, \mathrm{a}_{2}, \cdots, \mathrm{a}_{\mathrm{m}}$. Assuming the next layer (B layer) contains $n$ elements: $B_{1}, B_{2}, \cdots, B_{n}$. Now seeking $B$ layer of the factors on the weight of the total goal, the total ordering of various factors of layer $B$ are $b_{1}, b_{2}, \cdots, b_{n}$. The calculation can be carried out by Eq. (3) as follows.

$b_{i}=\sum_{j=1}^{m} a_{j} b_{i j},(i=1,2, \cdots, n)$

Total ordering of hierarchy also needs testing consistency. The test is still like the layer of total sorting method to sort out the top layer by layer to lower layer by layer. Denote $C I_{j}$ as the consistency index of hierarchical order corresponding to the impact of $B_{j}$ on its upper layer $A_{j}$, and the random consistency index is denoted as $R I_{j}$. Then, the consistency ratio of total ordering of hierarchy can be computed by:

$C R=\frac{a_{1} a_{1}+a_{2} a_{2}+\cdots+a_{m} a_{m}}{a_{1} A_{1}+a_{2} A_{2}+\cdots+a_{m} A_{m}}$

When $\mathrm{CR}<0.1$, it is considered that total ordering of hierarchy is passing through consistency testing.

\subsection{Establishment of the Travel Route Decision Model}

\subsubsection{Indexes and Content of the Travel Route Assessment}

The judgment to travel route is a comprehensive and complicated problem. There are many factors that influence judgement, which influence collectively if travel route is optimal or worst[12]. In this paper, information about travel route in travel route decision system derives from well-known domestic travel websites (such as Tuniu website, 
Xiecheng website, Tongcheng website etc.). Considering the information listed on websites and all other factors, we chose some aspects as important assessment indexes for assessment of travel route, including price, the days of travel, means of transport, accommodation, scenic spot, dining arrangement and customer satisfaction. These indexes are introduced in details as follows.

(1) Price

Price is an important index to assess travel route. And it is an important factor for most consumers to consider firstly and select route.

(2) The days of travel

Because of limited time, the days of travel is an important factor for most tourists. Most travelers prefer spending less time to visit more scenic spots.

(3) means of transport

Means of transport is always concerned by travelers. For a long journey, travelers prefer pursuing a comfortable and fast transportation.

(4) Scenic spot

Scenic spot is an important index to measure a travel route. It is a main factor concerned by tourists. They tend to choose a route that contains more interesting and well-reputed scenic spots.

(5) Accommodation

For tourists, accommodation is also an important factor. For example, some tourists like choosing four-star or better hotel.

(6) Dining Arrangement

Dining arrangement is an obbligato factor in group travel route and an index that must be considered.

(7) Customer satisfaction

The index of customer satisfaction derives from user commenting system of travel websites. On travel websites, each travel route corresponds with a customer satisfaction.

\subsubsection{Establishment of Hierarchy Structure Model}

The hierarchy structure model is shown in Fig. 2 below. The goal layer Z refers to travel routes for choosing. Criteria layer A contains indexes, including price, days of travel, means of transport, accommodation, scenic spot, dining arrangement, customer satisfaction. Scheme layer B refers to all alternative travel routes, that is, after users input place of departure and destination by the system, then comes out all travel routes. The comparability of the same index only exists among travel routes, so it is no longer to set secondary criteria layer below criteria layer. In scheme layer, travel routes that derives from the system by users input place of departure and destination. Therefore, the quantity of travel route is not sure. Route 1 to route $\mathrm{n}$ shows it as below. 


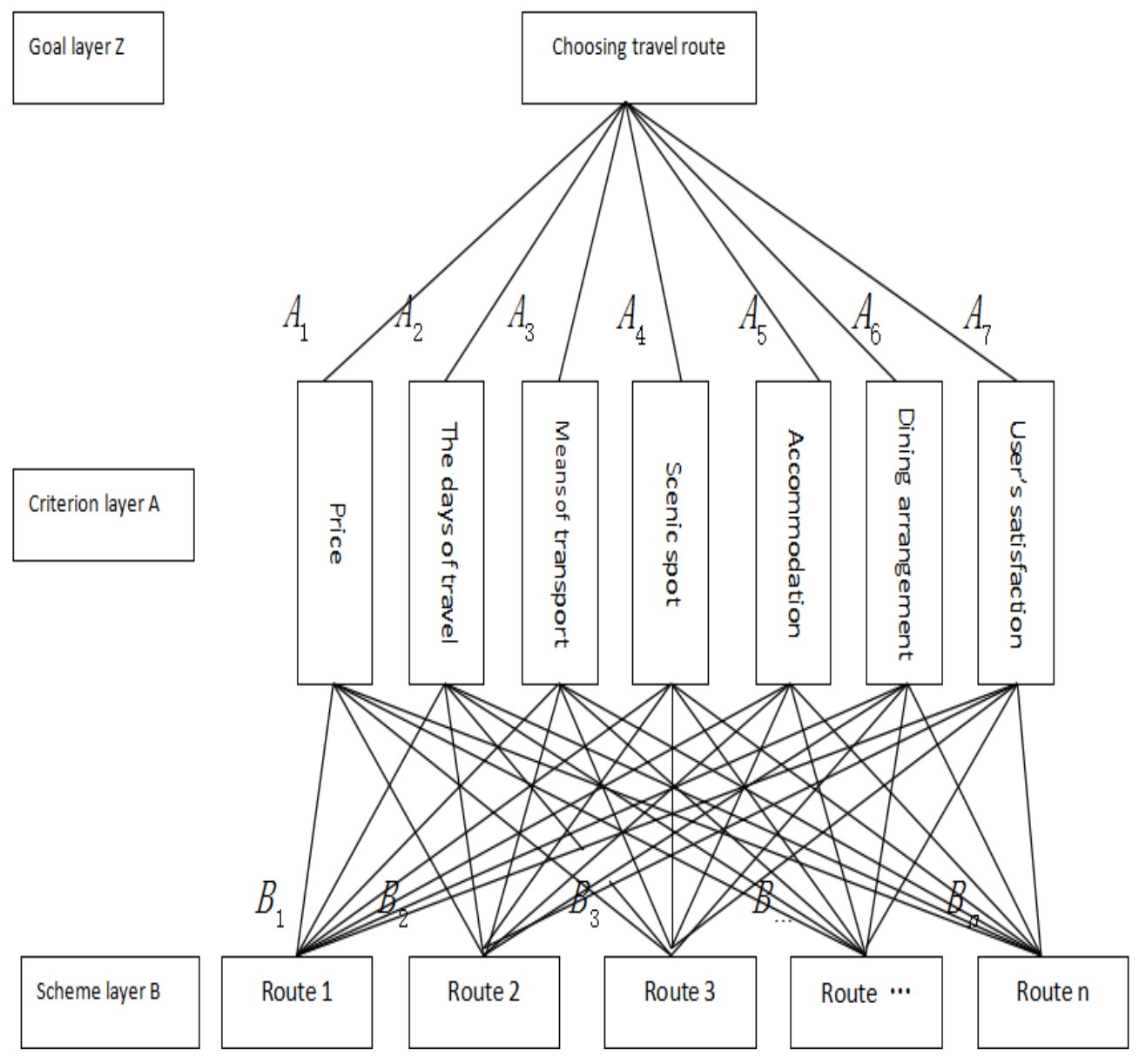

Figure 2. The Hierarchy Structure of Travel Route Decision

\subsubsection{Constructing Paired Comparison Matrix of Criteria Layer and Single Ordering of Hierarchy and Testing Consistency}

\subsubsection{The Constructing of Paired Comparison Matrix about Criteria Layer}

(1) According to experts' suggestions and combining with actual travel problems, constructing matrix is as follows.

$$
A=\left(\begin{array}{ccccccc}
1 & 5 & 5 & 3 & 7 & 9 & 3 \\
1 / 5 & 1 & 1 / 3 & 1 / 7 & 1 / 5 & 1 / 3 & 1 / 7 \\
1 / 5 & 3 & 1 & 1 / 5 & 1 & 3 & 1 / 3 \\
1 / 3 & 7 & 5 & 1 & 7 & 8 & 3 \\
1 / 7 & 5 & 1 & 1 / 7 & 1 & 2 & 1 \\
1 / 9 & 3 & 1 / 3 & 1 / 8 & 1 / 2 & 1 & 1 / 6 \\
1 / 3 & 7 & 3 & 1 / 3 & 1 & 6 & 1
\end{array}\right)
$$

According to 1-9 scaling theory mentioned before, numerical values in this judgment matrix suggest the weight relation between each index as follows:

$a_{12}=5$ : Price is obviously more important than the days of travel;

$a_{13}=5$ : Price is obviously more important than means of transport;

$a_{14}=3$ : Price is slightly more important than scenic spot; 
$a_{12}=7$ : Price is mightily more important than accommodation;

$a_{16}=9$ : Price is extremely more important than dining arrangement;

$a_{17}=3$ : Price is slightly more important than customer satisfaction;

Referring to 1-9 scaling theory mentioned before, other weight relation is similar, no longer repeated there.

(2) Establishing matrix through users' preferential choice, so matrix changes can be changed according to users' actual demand. That is more flexible and comprehensive. Establishing steps and process are the same as above process.

\subsubsection{The Consistency Test of Criterion Layer and Single Ordering of Hierarchy}

(1) Calculating normalized characteristic vector of the maximum characteristic root and the characteristic root according to comparison matrix above.

The maximum characteristic root calculated by using relevant tools and programs is, $\lambda_{\max }=7.7057$. The corresponding characteristic vector of characteristic root is $\omega=\{0.7579,0.0546,0.1312,0.5536,0.1495,0.0716,0.2673\}$

After the normalized processing,

$$
\omega=\{0.3817,0.0275,0.0661,0.2788,0.0753,0.0361,0.1346\}
$$

(2)The testing of consistency

Calculating the consistency index : $a=\frac{\lambda_{\max }-n}{n-1}=\frac{7.7057-7}{7-1} \approx 0.1176$

Calculating the consistency ratio: $C R=\frac{a}{R}=\frac{0.1176}{1.36} \approx 0.0865$

(The mean random consistency index RI can be achieved by use of a lookup table method). Since $O R<0.1$,it indicates matrix $\mathrm{A}$ is verified by consistency verification.

(3) The single-sorts of layer of criteria layer

Table 3. Each Index Weight of Criterion Layer

\begin{tabular}{|c|c|c|c|c|c|c|c|}
\hline criterion & Price & $\begin{array}{c}\text { Days } \\
\text { of } \\
\text { travel }\end{array}$ & $\begin{array}{c}\text { Means of } \\
\text { transportatio } \\
\mathrm{n}\end{array}$ & $\begin{array}{c}\text { Scenic } \\
\text { spots }\end{array}$ & $\begin{array}{c}\text { Accommodatio } \\
\mathrm{n} \text { condition }\end{array}$ & $\begin{array}{c}\text { Dining } \\
\text { arrangement } \\
\mathrm{s}\end{array}$ & $\begin{array}{c}\text { Customer } \\
\text { satisfactio } \\
\mathrm{n}\end{array}$ \\
\hline $\begin{array}{c}\text { Criterio } \\
\mathrm{n} \text { weight } \\
\left(\mathbf{a}_{k}\right)\end{array}$ & 0.3817 & 0.0275 & 0.0661 & 0.2788 & 0.0753 & 0.0361 & 0.1346 \\
\hline
\end{tabular}

\subsubsection{The Single-sorts and Total Sorts of the Scheme Layer and Testing Consistency}

\subsubsection{The Construction of Paired Comparison Matrix for Each Index of the Scheme Layer to Criterion Layer}

The scheme layer's paired comparison matrix to $\mathrm{A}_{\mathrm{i}}$ (every index of criterion layer)

$$
B_{i}=\left(\begin{array}{ccc}
b_{11} & \ldots & b_{1 n} \\
\vdots & \ddots & \vdots \\
b_{n 1} & \cdots & b_{n n}
\end{array}\right)
$$

We randomly seek out 5 travel routes which are roughly alike. Their paired 
comparison matrixes are respectively,

(1) the paired comparison matrix of scheme layer to $A_{1}$ (price)

$$
B_{1}=\left(\begin{array}{ccccc}
1 & \frac{1}{2} & 4 & 3 & 3 \\
2 & 1 & 7 & 5 & 5 \\
\frac{1}{4} & \frac{1}{7} & 1 & \frac{1}{2} & \frac{1}{3} \\
\frac{1}{3} & \frac{1}{5} & 2 & 1 & 1 \\
\frac{1}{3} & \frac{1}{5} & 3 & 1 & 1
\end{array}\right)
$$

(2) the paired comparison matrix of scheme layer to $\mathrm{A}_{2}$ (days of travel)

$$
B_{2}=\left(\begin{array}{ccccc}
1 & \frac{1}{2} & 3 & 3 & 3 \\
2 & 1 & 6 & 5 & 5 \\
\frac{1}{3} & \frac{1}{6} & 1 & \frac{1}{2} & \frac{1}{4} \\
\frac{1}{3} & \frac{1}{5} & 2 & 1 & 1 \\
\frac{1}{3} & \frac{1}{5} & 4 & 1 & 1
\end{array}\right)
$$

(3) the paired comparison matrix of scheme layer to $\mathrm{A}_{3}$ (means of transport)

$$
B_{3}=\left(\begin{array}{ccccc}
1 & 1 & 1 & 2 & 2 \\
1 & 1 & 1 & 2 & 2 \\
1 & 1 & 1 & 2 & 2 \\
\frac{1}{2} & \frac{1}{2} & \frac{1}{2} & 1 & 1 \\
\frac{1}{2} & \frac{1}{2} & \frac{1}{2} & 1 & 1
\end{array}\right)
$$

(4) the paired comparison matrix of scheme layer to $\mathrm{A}_{4}$ (scenic spots)

$$
B_{4}=\left(\begin{array}{ccccc}
1 & \frac{1}{2} & 2 & 1 & \frac{1}{3} \\
2 & 1 & 3 & 2 & 1 \\
\frac{1}{2} & \frac{1}{3} & 1 & \frac{1}{2} & \frac{1}{5} \\
1 & \frac{1}{2} & 2 & 1 & \frac{1}{2} \\
3 & 1 & 5 & 2 & 1
\end{array}\right)
$$

(5)the paired comparison matrix of scheme layer to $\mathrm{A}_{5}$ (accommodation of condition ) 


$$
B_{5}=\left(\begin{array}{ccccc}
1 & 3 & \frac{1}{2} & 1 & 2 \\
\frac{1}{3} & 1 & \frac{1}{4} & \frac{1}{3} & \frac{1}{2} \\
2 & 4 & 1 & 2 & \frac{1}{3} \\
1 & 3 & \frac{1}{2} & 1 & 1 \\
\frac{1}{2} & 2 & 3 & 1 & 1
\end{array}\right)
$$

(6) the paired comparison matrix of scheme layer to $A_{6}$ (dining arrangements)

$$
B_{6}=\left(\begin{array}{ccccc}
1 & 1 & 1 & 4 & 1 \\
1 & 1 & 2 & 4 & 1 \\
1 & \frac{1}{2} & 1 & 5 & 3 \\
\frac{1}{4} & \frac{1}{4} & \frac{1}{5} & 1 & \frac{1}{3} \\
1 & 1 & \frac{1}{3} & 3 & 1
\end{array}\right)
$$

(7) the paired comparison matrix of scheme layer to $\mathrm{A}_{7}$ (customer satisfaction)

$$
B_{7}=\left(\begin{array}{ccccc}
1 & 1 & 2 & 1 & 2 \\
1 & 1 & 2 & 1 & 2 \\
\frac{1}{2} & \frac{1}{2} & 1 & \frac{1}{2} & 2 \\
1 & 1 & 2 & 1 & 2 \\
\frac{1}{2} & \frac{1}{2} & \frac{1}{2} & \frac{1}{2} & 1
\end{array}\right)
$$

\subsubsection{The Consistency Test of the Scheme Layer and Single Ordering of Hierarchy}

Using relevant tools or programs to calculate the characteristic root according to characteristic vector of every comparison matrix (and make normalized processing),

\begin{tabular}{|c|c|c|c|c|c|c|c|c|}
\hline \multicolumn{2}{|c|}{ Criterion } & Price & $\begin{array}{l}\text { Days } \\
\text { of } \\
\text { travel }\end{array}$ & $\begin{array}{l}\text { Means } \\
\text { of } \\
\text { transpo } \\
\text { rtation }\end{array}$ & $\begin{array}{c}\text { Scenic } \\
\text { spots }\end{array}$ & $\begin{array}{c}\text { Accom } \\
\text { modatio } \\
n \\
\text { conditio } \\
n\end{array}$ & $\begin{array}{c}\text { Dining } \\
\text { arrange } \\
\text { ments }\end{array}$ & $\begin{array}{c}\text { Custo } \\
\text { mer } \\
\text { satisf } \\
\text { actio } \\
\text { n }\end{array}$ \\
\hline \multirow{5}{*}{$\begin{array}{l}\text { Singl } \\
\text { e- } \\
\text { sorts } \\
\text { weig } \\
\text { ht }\end{array}$} & $\begin{array}{c}\text { Rout } \\
\text { e1 }\end{array}$ & $\begin{array}{c}0.26 \\
36\end{array}$ & o. 2547 & 0. 2500 & o. 1397 & o. 2273 & 0. 2215 & $\begin{array}{c}0.24 \\
82\end{array}$ \\
\hline & $\begin{array}{c}\text { Rout } \\
\text { e2 }\end{array}$ & $\begin{array}{c}0.84 \\
09\end{array}$ & 0. 4670 & 0. 2500 & 0. 2870 & 0.0718 & O. 2734 & $\begin{array}{c}0.24 \\
82\end{array}$ \\
\hline & $\begin{array}{c}\text { Rout } \\
\text { e3 }\end{array}$ & $\begin{array}{c}0.09 \\
51\end{array}$ & O. 0579 & 0. 2500 & 0. 0769 & 0. 2579 & o. 2731 & $\begin{array}{c}0.14 \\
58\end{array}$ \\
\hline & $\begin{array}{c}\text { Rout } \\
\text { e4 }\end{array}$ & $\begin{array}{c}0.17 \\
33\end{array}$ & 0. 0990 & o. 1250 & 0. 1511 & 0. 1806 & 0. 0556 & $\begin{array}{c}0.24 \\
82\end{array}$ \\
\hline & $\begin{array}{c}\text { Rout } \\
\text { e5 }\end{array}$ & $\begin{array}{c}0.19 \\
20\end{array}$ & o. 1213 & o. 1250 & o. 3453 & 0. 2624 & O. 1764 & $\begin{array}{c}0.10 \\
97\end{array}$ \\
\hline
\end{tabular}
which is shown in the following table 4.

Table 4. The Paired Comparison Matrix of Vector Table to the Criterion Layer 
Using relevant tools or programs to calculate the maximum characteristic root of every matrix and then calculate the consistency index CI and the consistency ratio CR with formula mentioned before, as shown in Table 5.

\section{Table 5. The Schedule of Proportion of Paired Comparison Matrix's Largest Eigenvalue and Correspondence to the Criterion Layer}

\begin{tabular}{|c|c|c|c|c|c|c|c|}
\hline criterion & Price & $\begin{array}{c}\text { Day } \\
\text { s of } \\
\text { trave } \\
1\end{array}$ & $\begin{array}{c}\text { Means } \\
\text { of } \\
\text { transpor } \\
\text { tation }\end{array}$ & $\begin{array}{c}\text { Scen } \\
\text { ic } \\
\text { spots }\end{array}$ & $\begin{array}{c}\text { Accommoda } \\
\text { tion } \\
\text { condition }\end{array}$ & $\begin{array}{c}\text { Dining } \\
\text { arrangem } \\
\text { ents }\end{array}$ & $\begin{array}{c}\text { Custome } \\
\text { r } \\
\text { satisfacti } \\
\text { on }\end{array}$ \\
\hline$\lambda \max$ & $\begin{array}{c}5.072 \\
1\end{array}$ & $\begin{array}{c}5.19 \\
34\end{array}$ & 5 & $\begin{array}{c}5.03 \\
37\end{array}$ & 5.4176 & 5.2668 & 5.0586 \\
\hline $\begin{array}{c}\text { Consistency } \\
\text { index CI }\end{array}$ & $\begin{array}{c}0.018 \\
0\end{array}$ & $\begin{array}{c}0.04 \\
84\end{array}$ & 0 & $\begin{array}{c}0.00 \\
84\end{array}$ & 0.1544 & 0.0667 & 0.0147 \\
\hline $\begin{array}{c}\text { Consistency } \\
\text { ratio CR }\end{array}$ & $\begin{array}{c}0.016 \\
0\end{array}$ & $\begin{array}{c}0.04 \\
32\end{array}$ & 0 & $\begin{array}{c}0.00 \\
75\end{array}$ & 0.0932 & 0.0596 & 0.0131 \\
\hline
\end{tabular}

From the table above, consistency ratio CR of each single layer is lower than 0.1 and each layer's consistency ratio passes the emission.

$C R=\frac{a_{1} a_{1}+a_{2} a_{2}+\cdots+a_{m} a_{m}}{a_{1} A_{1}+a_{2} A_{2}+\cdots+a_{m} A_{m}}=\frac{0.00202}{1.12}=0.0018<0.1$ (14)

Since $\mathrm{CR}<0.1$, the combinatorial consistency ratio passes the inspection.

\subsubsection{The Total Sorts and Decision-making}

Finally, we sort out single-sorts weight of each layer and then calculate the weight of total sorts, which is exposed as Table 6.

Table 6. The Final Route Sorting Weight Table

\begin{tabular}{|c|c|c|c|c|c|c|c|c|c|}
\hline \multicolumn{2}{|c|}{ Criterion } & Price & $\begin{array}{l}\text { Days } \\
\text { of } \\
\text { travel }\end{array}$ & $\begin{array}{l}\text { Means } \\
\text { of } \\
\text { transpo } \\
\text { rtation }\end{array}$ & $\begin{array}{l}\text { Scenic } \\
\text { spots }\end{array}$ & $\begin{array}{l}\text { Accom } \\
\text { modati } \\
\text { on } \\
\text { conditi } \\
\text { on }\end{array}$ & $\begin{array}{c}\text { Dining } \\
\text { arrange } \\
\text { ments }\end{array}$ & $\begin{array}{l}\text { Customer } \\
\text { satisfacti } \\
\text { on }\end{array}$ & \multirow{2}{*}{$\begin{array}{c}\text { Al1- } \\
\text { sorts } \\
\text { weight }\end{array}$} \\
\hline \multicolumn{2}{|c|}{$\begin{array}{c}\text { The criterion } \\
\text { layer's } \\
\text { weight }\end{array}$} & 0.3817 & 0.0275 & 0.0661 & 0.2788 & 0.0753 & 0.0361 & 0.1346 & \\
\hline \multirow{5}{*}{$\begin{array}{l}\text { Single } \\
\text {-sorts } \\
\text { weigh } \\
\text { t }\end{array}$} & $\begin{array}{c}\text { Route } \\
1\end{array}$ & 0.2636 & 0.2547 & 0.2500 & 0. 1397 & 0.2273 & 0.2215 & 0.2482 & 0. 2216 \\
\hline & $\begin{array}{c}\text { Route } \\
\quad 2\end{array}$ & 0.8409 & 0.4670 & 0.2500 & 0.2870 & 0.0718 & 0.2734 & 0.2482 & 0.4790 \\
\hline & $\begin{array}{l}\text { Route } \\
3\end{array}$ & 0.0951 & 0.0579 & 0.2500 & 0.0769 & 0.2579 & 0.2731 & 0.1458 & 0.1248 \\
\hline & $\begin{array}{c}\text { Route } \\
4\end{array}$ & 0.1733 & 0.0990 & 0.1250 & 0.1511 & 0.1806 & 0.0556 & 0.2482 & 0.1683 \\
\hline & $\begin{array}{c}\text { Route } \\
5\end{array}$ & 0. 1920 & 0.1213 & 0. 1250 & 0.3453 & 0.2624 & 0.1764 & 0.1097 & 0. 2220 \\
\hline
\end{tabular}

According to the total sorts weight, we can make a conclusion that the best travel route is route 2 . The total weight of each route is respectively $0.4790,0.2216,0.2220$, $0.1683,0.1248$. On the basis of decision-making model raised in the paper, the order of travel route from top to end is $2,1,5,4,3$. Till here, decision-making problems of travel routes are all solved. 


\section{The Verification of the Results About Travel Route Decision-making}

Because this decision method is to establish criterion layer based on the multiple indicator, and indicator will involve a lot of subjective and qualitative indexes, so for the results in this section, we choose the quantitative ones in these indicators, then make a fuzzy comparison with the decision-making result that we have get, thus testing veracity of results about travel route decision-making. Table 7 shows five routes of quantitative information.

Table 7. Some Information for Travel Route

\begin{tabular}{|c|c|c|c|c|}
\hline criterion & price & $\begin{array}{c}\text { the day of } \\
\text { travel }\end{array}$ & $\begin{array}{c}\text { means of } \\
\text { transportati } \\
\text { on }\end{array}$ & $\begin{array}{c}\text { customer } \\
\text { satisfaction }\end{array}$ \\
\hline route 1 & 1920 & 4 & airport & $95 \%$ \\
\hline route 2 & 1700 & 5 & airport & $95 \%$ \\
\hline route 3 & 3000 & 7 & airport & $92 \%$ \\
\hline route 4 & 2450 & 7 & train & $95 \%$ \\
\hline route 5 & 2450 & 7 & train & $92 \%$ \\
\hline
\end{tabular}

According to above data, we can simply make the line chart of each route. According to the actual problem, we make means of transport in the scope set to $(0,1)$. The line chart below in Fig. 3.

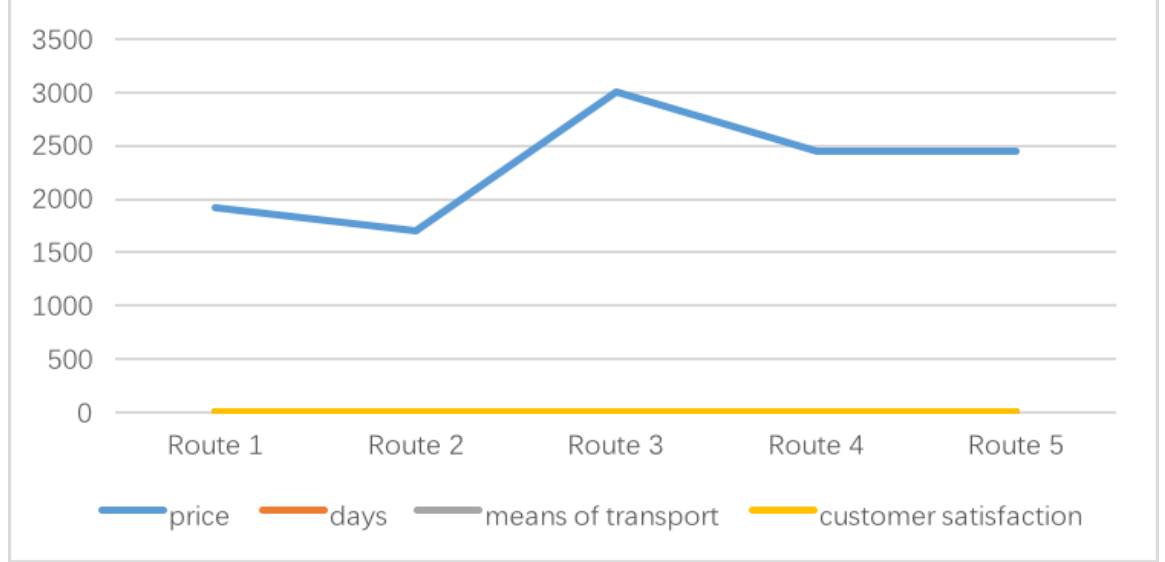

Figure 3. The Line Chart about Every Index of Travel Route

From Fig. 3, we can see that, due to the large numerical difference between various indicators, this figure does not reflect too much information. Here we need to do simply data processing.

First of all, we need to make consistency processing for every index data from the given route above. Here we'll introduce the concept of cost performance. Popularly speaking, cost performance equals to the price/performance [13]. In response to the actual problems, fuzzy cost performance formula of travel route is given here. $\mathrm{F}(\mathrm{x})$ represents a cost-effective, $d$ represents travel days, $t$ represents the means of transport, $p$ represents price, $\mathrm{s}$ represents satisfaction [13].

$$
F(x)=\frac{d^{*} t}{p} * s
$$

Through above formula, we can get cost performance and then draw the line chart, as 
shown in Fig. 4. Finally, from the Fig. 5, we can see that total weight and the line chart of cost performance behavior are anastomotic in principle, abscissas of both line chart peak are route 2 , which means the optimal travel route is route 2 . Therefore, it can make a conclusion, within a certain range of assessment error , the optimal travel route proposed in this paper is basically accurate and meanwhile has a certain reliability.

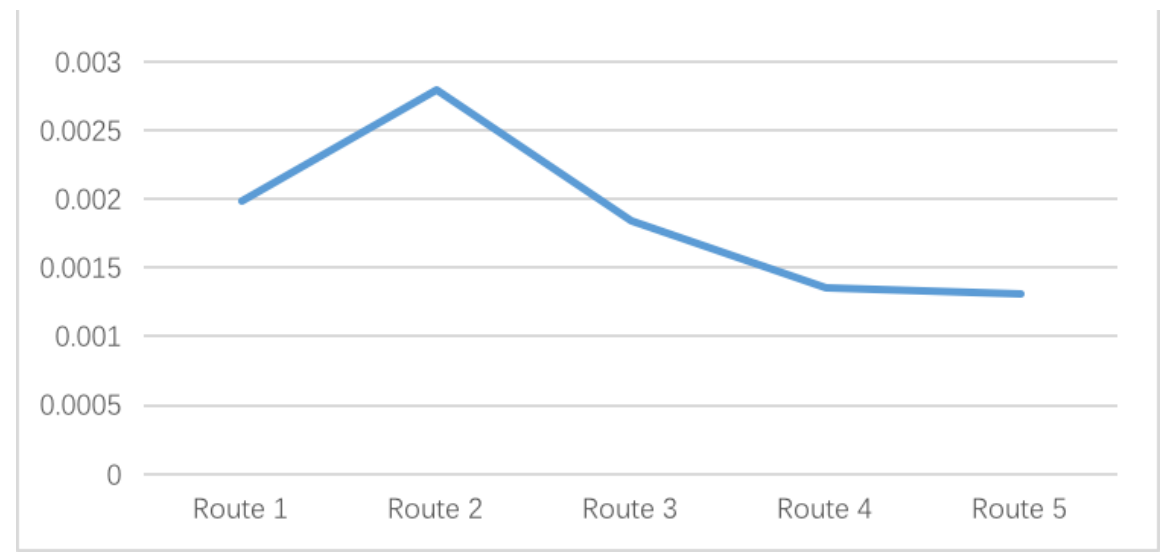

Figure 4. The Line Chart about Fuzzy Cost Performance of Every Route

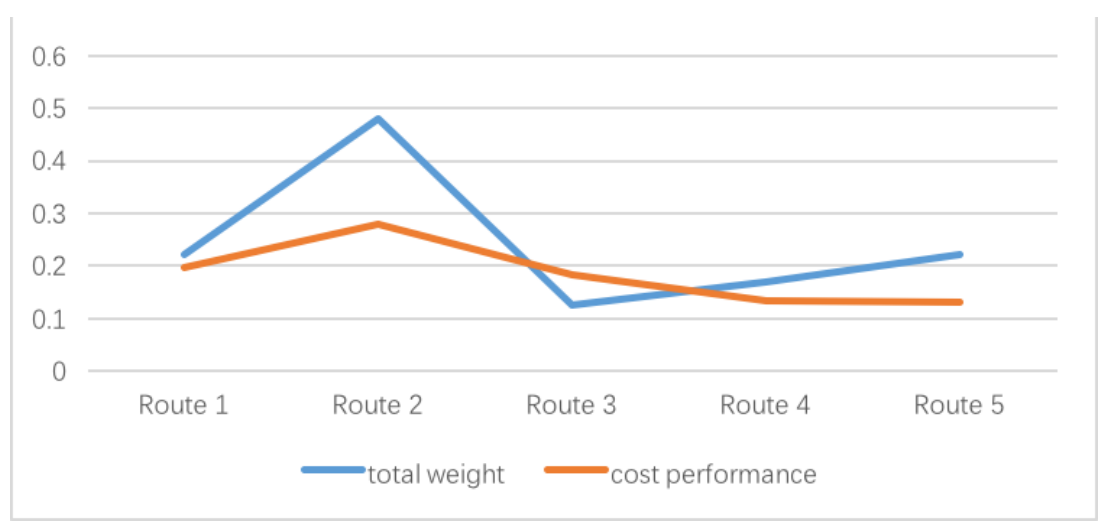

Figure 5. The Comparison Line Chart of Cost Performance and Total Weight about Every Route

\section{Conclusion and Future Work}

In this paper, according to decision support model and travel routes of online travel websites as data support, we propose and construct decision model of optimal travel route based on the Analytic Hierarchy Process, and make the consistency test. Finally, we use proposed fuzzy cost performance formula to verify decision result. It is found that the optimal route is basically accurate, so it offers convenience to users to choose optimal the travel route on travel websites.

Along with the scientific and technological progress, social development, great increase of knowledge and information, problems need to be made decision are getting more and more difficult and complicated. Specifically, the vagueness of decision makers' cognition, the uncertainty of decision environment, the multi-source heterogeneity of decision information, dynamic changes of decision process and other factors lead to complexity of decision problems. This paper solved the problem in choosing optimal travel route by means of optimal travel route decision model. When constructing paired comparison matrix of criteria layer, users can construct judgement matrix according to their own preferences and actual demand, which shows model's flexibility. Meanwhile, the model is combined with cloud computing technology, integrating information of 
travel routes on online travel websites. On the one hand, it enables model to provide more available inputting schemes, which guarantees accuracy and comprehensiveness of decision. On the other hand, it offers users more selection schemes, which is more scientific and reasonable. However, the decision model of optimal travel route based on AHP needs more researches in the following cases.

(1) AHP hierarchical decision-making model is influenced more by artificial and subjective factors.

This model has certain limitations. In this paper, when constructing paired comparison matrix of scheme layer, decision-makers have to judge subjectively each route which is effected by different factors and then construct paired comparison matrix. The problem of this method is that it's unable to construct matrix quickly and efficiently. The model is also complicated and semi-automatic in some ways. The researchers may consider using the technology of machine learning[14] and word segmentation[15] which enables machine to compare every index of travel routes with influence of scheme layer's factors automatically, and then construct comparison matrix. It will improve efficiency of decision-making.

(2) When there are too many schemes in scheme layer, performance of the decision model will decline.

When there are too many schemes in scheme layer, firstly, it takes a great deal of resources and time to compare routes and thus efficiency will decline. Secondly, the core idea of model is constructing comparative judgment matrix. So if the amount of scheme layer is too large, order of the matrix will increase accordingly. Yet, higher order of the matrix will cause difficulties in calculating the maximum eigenvalue and eigenvector. In this way, efficiency of solving the problem will decline and cost of resources will rise. Therefore, the optimization to the number of scheme layer is an important factor that should be considered in this model.

\section{Acknowledgments}

This paper is partially supported by The National Natural Science Foundation of China (No. 61363019, No. 61440021, No. 61272087, No.61073008 and No.61563044); National Natural Science Foundation of Qinghai Province (No. 2014-ZJ-718, No. 2015-ZJ-725).

\section{References}

[1] C. Lijun, "An empirical analysis of the domestic tourism development status and economic factors", Commercial Accounting, vol. 14, (2015), pp. 110-112.

[2] http://gny.ly.com (Tongcheng website in China)

[3] Z.-B. Ma, "Research methods and techniques of tourists travel decision support system", Shandong university of science and technology, (2009), pp. 54-58.

[4] B.-H. Jin, "Travel route choice model based on regret theory", Computer Modeling \& New Technologies, vol. 18, no. 4, (2014), pp. 158-163

[5] L. Wang, "Construction and application of urban tourism competitiveness evaluation index system based on AHP", History and Culture College, (2014), pp. 1003-2363.

[6] G.-L. Li, "Multistage fuzzy multiple criteria decision-making method", The university of electronic science and technology, (2015).

[7] D.-R. Liu, "Integrating AHP and data mining for product recommendation based on customer lifetime value", Information \& Management, vol. 42, (2005), pp. 387-400.

[8] M. Gupta, "Design of a AHP Based User Centric Decision Making Algorithm for Network Selection", ICCCT '15: Proceedings of the Sixth International Conference on Computer and Communication Technology , (2015).

[9] T. E. Erkan and G. F. Can, "Selecting the Best Warehouse Data Collecting System by Using AHP AND FAHP Methods, Tehnički vjesnik, vol. 21, no. 1, (2014), pp. 87-93.

[10] L. Li, "Analysis and research of AHP-based method base", Applied Mechanics and Materials, Frontiers of Manufacturing and Design Science II, vol. 121-126, (2012), pp. 4382-4385.

[11] M. M. G. Elbarkouky, "An AHP approach for consultant selection in Real Estate mega projects in the 
Middle East”, Proceedings, Annual Conference - Canadian Society for Civil Engineering, Annual Conference of the Canadian Society for Civil Engineering, (2013).

[12] J. Solomon, "Customization bias in decision support systems", CHI Proceedings of the SIGCHI Conference on Human Factors in Computing Systems, (2014).

[13] K.-J. Choi, "Cost performance analysis in multi-level tree networks", 9th International Symposium on Parallel and Distributed Computing, ISPDC, (2010).

[14] M. Dušan, "Soft computing prediction of economic growth based in science and technology factors", Physica A: Statistical Mechanics and its Applications, vol. 465, (2017), pp. 217-220.

[15] M. Elhenawy, "Modeling the perception reaction time and deceleration level for different surface conditions using machine learning techniques", IFIP Advances in Information and Communication Technology, ICT for Promoting Human Development and Protecting the Environment - 6th IFIP World Information Technology Forum, WITFOR, vol. 481, (2016), pp. 131-142.

\section{Authors}

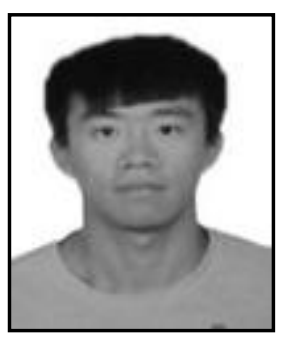

\section{Peng Cui}

Undergraduate/Student

Research field: Cloud computing, Artificial Intelligence.

Phone number: +86-18103433890

Email: xpeng.cui@foxmail.com

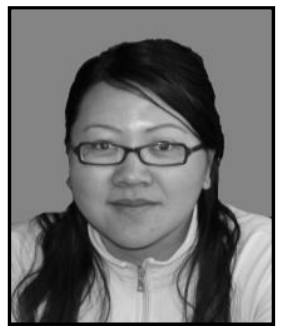

\section{Xiaoying Wang \\ $\mathrm{PhD} /$ Professor}

Research field: High performance computing, green computing

Phone number: +86-0971-5311115

Email: xy.wang@foxmail.com 
International Journal of Grid and Distributed Computing

Vol. 10, No. 2 (2017) 